Article

\title{
A 5-Methylcytosine Site of Growth Differentiation Factor 9 (GDF9) Gene Affects Its Tissue-Specific Expression in Sheep
}

\author{
Zhangyuan Pan ${ }^{1,2}{ }^{,}$Xiangyu Wang ${ }^{1}$, Ran $\mathrm{Di}^{1}{ }^{1}$, Qiuyue Liu ${ }^{1}$, Wenping $\mathrm{Hu}{ }^{1}$, Xiaohan Cao ${ }^{1}$, \\ Xiaofei Guo ${ }^{1}$, Xiaoyun $\mathrm{He}^{1}$, Shengjin $\mathrm{Lv}^{2}$, Fukuan $\mathrm{Li}^{2}$, Hui Wang ${ }^{2}$ and Mingxing Chu ${ }^{1, *}$ \\ 1 Key Laboratory of Animal Genetics and Breeding and Reproduction of Ministry of Agriculture, Institute of \\ Animal Science, Chinese Academy of Agricultural Sciences, Beijing 100193, China; \\ pzq170450077@163.com (Z.P.); xiangyu_wiggle@163.com (X.W.); dirangirl@163.com (R.D.); \\ qiuyue1983921@163.com (Q.L.); pinkyhoho@163.com (W.H.); caoxiaohan2007@hotmail.com (X.C.); \\ guoxfnongda@163.com (X.G.); hexy2015x@163.com (X.H.) \\ 2 College of Agriculture and Forestry Science, Linyi University, Linyi 276000, China; \\ lvshenjin@lyu.edu.cn (S.L.); lifukuan@lyu.edu.cn (F.L.); wanghui0512@lyu.edu.cn (H.W.) \\ * Correspondence: mxchu@263.net; Tel.: +86-10-6281-9850
}

Received: 31 July 2018; Accepted: 24 October 2018; Published: 7 November 2018

Simple Summary: Growth differentiation factor 9 (GDF9) is an important gene for ovine fertility. GDF9 is highly expressed in the ovary as opposed to other tissues, but the reason for this is unknown. Our study found this can be caused by the methylation level of the promoter $\mathrm{CpG}$ island $\mathrm{mC}-4$ site. This finding contributes to the understanding of the regulatory mechanism of GDF9 gene in reproduction.

\begin{abstract}
Growth differentiation factor 9 (GDF9) plays an important role in the early folliculogenesis of sheep. This study investigated the mRNA expression of ovine GDF9 in different tissues by real-time PCR. GDF9 exhibits significantly higher levels of expression $(p<0.01)$ in the ovary, relative to other tissues, indicating that its expression is tissue specific. To explore the regulatory mechanism of this tissue-specific expression, the methylation level of one CpG island ( -1453 to -1854$)$ of GDF9 promoter in ovary and heart was determined. In this region (-1987 to -1750), only the mC-4 site was present in the Sp4 binding site showed differential methylation between the heart and ovary; with increased $(p<0.01)$ methylation being observed in the heart. Additionally, the methylation level was negatively correlated with GDF9 mRNA expression $(R=-0.75, p=0.012)$, indicating that the methylation of this site plays an important role in transcriptional regulation of GDF9. The methylation effect of the mC-4 site was confirmed by using dual-luciferase. Site-directed mutation (methylation) of mC-4 site significantly reduced $(p<0.05)$ basal transcriptional activity of GDF9 promoter in oocytes. These results imply that methylation of GDF9 promoter $\mathrm{CpG}$ island $\mathrm{mC}-4$ site may affect the binding of the $\mathrm{Sp} 4$ transcription factor to the GDF9 promoter region in sheep, thereby regulating GDF9 expression and resulting in a tissue-specific expression.
\end{abstract}

Keywords: GDF9; methylation; mRNA expression; tissue-specific; regulatory mechanism

\section{Introduction}

Growth differentiation factor 9 (GDF9) is a member of the transforming growth factor beta superfamily and was first identified in the human ovary [1]. In GDF9-deficient female mice, follicular development is halted at the single-layer primary follicle stage, causing infertility [2]. In sheep, GDF9 mutations $\left(\mathrm{FecG}^{\mathrm{H}}, \mathrm{FecG}^{T}, \mathrm{FecG}^{\mathrm{E}}, \mathrm{FecG}^{\mathrm{F}}\right.$, and $\left.\mathrm{FecG}^{V}\right)$ resulted in hyperprolificacy in heterozygotes 
and sterility in homozygotes [3-8]. Furthermore, a recent study discovered highly heritable markers within GDF9, which are important in determining prolificacy traits in sheep [9]. Thus, GDF9 is an important candidate gene in ovine fertility.

GDF9 is highly expressed in the ovaries of many species [10-14]. In sheep, GDF9 expression was higher in both fetal and adult ovaries when compared to expression in other tissues, indicating that GDF9 is tissue-specific [15-17]. GDF9 also followed a stage-specific pattern of expression during the in vivo development of ovarian follicles in sheep $[18,19]$. Although several studies have investigated the role of ovine GDF9 in ovarian function $[20,21]$ and the transcriptional regulation of a mutation of GDF9 in the ovaries of Fetal sheep [22], the underlying transcriptional mechanisms leading to the tissue-or stage-specific expression of GDF9 in sheep remain unclear.

Gene promoters are critical cis-regulatory elements for gene transcription that can drive tissue-specific gene expression [23,24]. The methylation of a promoter sequence is an important type of epigenetic control of gene expression [25]. Moreover, the methylation of a gene promoter may result in tissue-specific gene expression [26,27]. In a recent study, we cloned and analyzed the ovine GDF9 5' flanking sequence and found that it included a CpG island [28]. Then, to determine whether the methylation of this CPG island can lead to tissue-specific expression. In this study, GDF9 mRNA levels in ten tissues were verified using real-time PCR, after which we performed a dual-luciferase assay and site-directed mutation analysis to investigate the relationship between the tissue-specific expression of GDF9 and the methylation of a CPG island in the GDF9 promoter. Our results provide important insight into the regulatory mechanism of GDF9.

\section{Materials and Methods}

\subsection{Animals}

Small Tail Han (STH) sheep is a famous prolific breed, and the litter size can exceed 2.61 [29]. Five Small Tail Han (STH) ewes were raised on the same farm in Ningxia Hui Autonomous Region, China. Healthy sheep (3-4 years of age) were slaughtered after evidence of estrous in response to teaser rams. Tissues were harvested, snap-frozen in liquid nitrogen, and then stored at $-80^{\circ} \mathrm{C}$. Ten tissues samples (heart, liver, lung, spleen, uterus, oviduct, ovary, cerebellum, pituitary, and hypothalamus) were collected from each animal for tissue expression and DNA methylation analysis.

The experimental procedures were approved by the Institute of Animal Sciences, Chinese Academy of Agricultural Sciences (IASCAAS-AE-03).

\subsection{Detection of GDF9 Expression by Real-Time PCR}

RNA extraction was performed following the manufacturer's instructions using TRIzol reagent (TaKaRa, Dalian, China), and was treated with DNase using a TURBO DNA-free Kit (Ambion, Austin, TX, USA). The cDNA was generated by PrimeScriptTM ${ }^{\mathrm{RT}}$ reagent kit (TaKaRa, Dalian, China).

GDF9 primers (Exon-span) for real-time PCR were designed according to NM_001142888.2 using Primer-BLAST (NCBI). $20 \mu \mathrm{L}$ of reaction mixture of real-time PCR including cDNA $(2 \mu \mathrm{L}), 10 \mu \mathrm{M}$ each primer $(0.4 \mu \mathrm{L})$, ROX Reference Dye II $(50 \times)(0.4 \mu \mathrm{L})$, SYBR Green Master Mix $(2 \times)(10 \mu \mathrm{L})$, and $\mathrm{ddH}_{2} \mathrm{O}(6.8 \mu \mathrm{L})$. Reactions were performed under the following conditions: $30 \mathrm{~s}$ of $95^{\circ} \mathrm{C}$, followed by 40 cycles of $95^{\circ} \mathrm{C}$ for $5 \mathrm{~s}$ and $34 \mathrm{~s}$ of $60^{\circ} \mathrm{C}$. Negative control reactions were carried out without template. Each reaction was performed in triplicate wells. The amplification efficiency was evaluated using a standard curve. Table 1 lists the primers that were used for real-time PCR. GAPDH served as the normalization control. 
Table 1. Primers used in this study.

\begin{tabular}{|c|c|c|c|}
\hline Primer & Primer Sequence $\left(5^{\prime} \rightarrow 3^{\prime}\right)$ & $\begin{array}{c}\text { Annealing } \\
\text { Temperature }\left({ }^{\circ} \mathrm{C}\right)\end{array}$ & $\begin{array}{l}\text { Amplified DNA } \\
\text { Fragment (bp) }\end{array}$ \\
\hline \multicolumn{4}{|c|}{ Primers used in real-time PCR } \\
\hline GDF9-YG-F & CAGACGCCACCTCTACAACA & \multirow{2}{*}{60} & \multirow{2}{*}{197} \\
\hline GDF9-YG-R & CAGGAAAGGGAAAAGAAATGG & & \\
\hline GAPDH-F & GAGAAACCTGCCAAGTATGA & \multirow{2}{*}{60} & \multirow{2}{*}{139} \\
\hline GAPDH-R & CGAAGGTAGAAGAGTGAGTG & & \\
\hline \multicolumn{4}{|c|}{ Primers used in promoter activity analysis } \\
\hline $\mathrm{P} 1 \mathrm{~F}$ & CGGGGTACCACTATATGGCCAAGTAAATCTGAATC & 58 & 228 \\
\hline $\mathrm{P} 2 \mathrm{~F}$ & CGGGGTACCGTTCTCTGCTCTCTGGAATCTCAATTTC & 58 & 591 \\
\hline P3F & CGGGGTACCCCTGATCTTAGCTCAGAGGCAAGAAC & 58 & 899 \\
\hline $\mathrm{P} 4 \mathrm{~F}$ & CGGGGTACCTGTCATGTTGCCCACTGTTCACTGCC & 58 & 1299 \\
\hline P5F & CGGGGTACCGGCTTTCGTCGGAG & 58 & 1750 \\
\hline P6F & CGGGGTACCCCACTTCCGGTAGATCGGACG & 58 & 1987 \\
\hline P7F & CGGGGTACCCTGCTCGAAGGGCGACAAGCTAT & 58 & 2277 \\
\hline PR & GTCGTCAAGCTTGGCTTGGAAGAATTAGCAAGG & - & - \\
\hline \multicolumn{4}{|c|}{ Primers used in methylation analysis } \\
\hline M1F & GGGATTTGTCGTCGTTAAT & \multirow{2}{*}{55} & \multirow{2}{*}{352} \\
\hline M1R & CAAAACCCGCCCAAAAAC & & \\
\hline
\end{tabular}

\subsection{Sequence Analysis of GDF9 5'-Flanking Sequence}

The 2304 bp 5'-flanking sequence of GDF9 has been validated in a recent study [28]. The CpG islands were predicted using MethPrimer (http:/ / www.urogene.org/cgi-bin/methprimer/ methprimer.cgi). The transcription binding site was analyzed with Matinspector (solution parameters: core similarity 1.0; matrix-optimised) (Table 2) and Signal Scan (https:/ /www-bimas.cit.nih.gov/ molbio/signal/).

Table 2. Identification of the putative cis-regulatory elements upstream of ovine growth differentiation factor 9 (GDF9).

\begin{tabular}{lcllc}
\hline TFs & Description & Position & \multicolumn{1}{c}{ Sequence } & Strand \\
\hline AP-2 & Transcription factor AP-2, beta & $-1669,-1655$ & gctGCCCtagggtcg & + \\
SP4 & Sp4 transcription factor & $-1796,-1780$ & tcccgggGCGCCcccca & + \\
ATF & Activating transcription factor 1 & $-1867,-1847$ & cccacttcACGTcacgcggcg & - \\
EBOX & E-box binding factors & $-1869,-1853$ & cccgcgCGTGacgtga & + \\
USF & Upstream stimulating factor 1 & $-1870,-1854$ & cacgTCACgcggcgggg & - \\
CREB & cAMP-responsive element binding protein & $-1916,-1896$ & gtctccaggTGACggcgccat & + \\
ERRG & Estrogen-related receptor gamma binding site & $-1960,-1938$ & ccaggaggcggtgaGGTCacttc + & + \\
ER2 & Estrogen receptor 2 (ER beta) & $-2034,-2016$ & cgagGTCActtcgccact & + \\
ERRB & Estrogen-related receptor beta & $-2045,-2023$ & cactcacacaccgAGGTcacttc & + \\
\hline
\end{tabular}

\subsection{DNA Isolation and Bisulfite Treatment}

Heart and ovary tissues from each of the five STH sheep were used for methylation analysis. Genomic DNA was isolated by QIAamp DNA Mini Kit (QIAGEN, Valencia, CA, USA), and $1 \mu \mathrm{g}$ of DNA was converted using the EpiTect Bisulfite Kit (QIAGEN, Valencia, CA, USA), according to the manufacturer's manual. After the chemical conversion, each unmethylated cytosine was converted to an uracil, whereas each methylated cytosine was protected.

\subsection{Bisulfite Sequencing}

The methylation status of one CpG island $(-1854,-1453)$ of GDF9 was analyzed by bisulfite sequencing PCR (BSP) method. The BSP primers were designed by the MethPrimer program 
(http:/ / www.urogene.org/methprimer/) (Table 1). The reaction volume of $20 \mu \mathrm{L}$ contained $1 \mu \mathrm{L}$ of bisulfite-treated genomic DNA, $10 \mu \mathrm{L}$ of Taq master mix, $8 \mu \mathrm{L}$ of $\mathrm{ddH}_{2} \mathrm{O}$, and $0.5 \mu \mathrm{L}$ each of forward and reverse primers $(10 \mu \mathrm{M})$. The PCR conditions were as follows: $95^{\circ} \mathrm{C}$ for $8 \mathrm{~min}, 34$ cycles of $95^{\circ} \mathrm{C}$ for $30 \mathrm{~s}, 55^{\circ} \mathrm{C}$ for $30 \mathrm{~s}, 72{ }^{\circ} \mathrm{C}$ for $30 \mathrm{~s}$, and $72{ }^{\circ} \mathrm{C}$ for $8 \mathrm{~min}$. Next, the PCR products were cloned into the pMD18-T vector (TaKaRa, Dalian, China), and 10 positive clones from each tissues of each animals were sequenced (Invitrogen, Shanghai, China).

\subsection{GDF9 Promoter Deletion Constructs}

The regulatory region of $2636 \mathrm{bp}$ fragment of GDF9 has been sequenced in a previous study (Pan et al. 2016). Primers were designed to amplify six fragments of this region. The P1 promoter fragment was obtained using P1F and PR primers (Table 1). A KpnI restriction site was added to the $5^{\prime}$ end of the forward primer, whereas a HindIII restriction site was added to the $5^{\prime}$ end of the reverse primer. The PCR products were cloned into the pMD18-T vector (TaKaRa). Thereafter, they were excised with KpnI and HindIII (NEB) and subcloned into the promoterless pGL3-basic vector (Promega, Madison, WI, USA). The recombinant constructs were designated as pGL3-basic-P1 (-1/-228), pGL3-basic-P2 (-1/-591), pGL3-basic-P3 (-1/-899), pGL3-basic-P4 (-1/-1299), pGL3-basic-P5 (-1/-1750), pGL3-basic-P6 (-1/-1987), and pGL3-basic-P7 (-1/-2277). Subsequently, the constructs were transfected into oocytes to detect luciferase activity.

\subsection{Site-Directed Mutation of Sp4 Binding Element}

A putative Sp4 transcription factor-binding site (-1790 bp) within the pGL3-Basic-P6 was mutated by Quick Change Lightning SDM kit (Stratagene, Santa Clara, CA, USA). Primer $5^{\prime}$ TCTGGGGTCCCGGGGAGCCCCCCACCGGATCC 3' with complementary reverse primer were used for PCR amplification of pGL3-Basic-P6-mut1. The resultant mutation was confirmed by sequencing. Then the constructs were transfected into oocytes to detect luciferase activity.

\subsection{In Vitro-Methylation}

According to the manufacturer's instructions of methylase M.SssI (New England Biolabs), two plasmids with methylated CpG promoters, pGL3-Basic-P6-methylation and pGL3-Basic-P5-methylation were generated. The methylation status was verified by methylation-sensitive restriction eyzyme NarI (New England Biolabs). After purification with QIAquick Nucleotide Removal Kit (QIAGEN, Valencia, CA, USA), the plasmids were transfected into oocytes to detect luciferase activity.

\subsection{Luciferase Assay}

According to the method in a previous report [30], a dual luciferase assay was performed in ovine oocytes. Ovaries were collected from a local abattoir, stored in PBS buffer (including streptomycin sulphate $100 \mu \mathrm{g} / \mathrm{mL}$ and penicillin $100 \mathrm{U} / \mathrm{mL}$ ) on ice, and transported to the laboratory within $4 \mathrm{~h}$. Next, the ovaries were washed three times in normal saline, and follicular fluid of large antral follicles $(3-6 \mathrm{~mm}$ ) was collected from the visible follicles with a sterile injector. Only cumulus oocyte complexes (COCs) with more than five layers of cumulus mass were selected. Pools of 30 COCs were incubated in standard medium (DMEM with 15\% FBS, 0.005\% streptomycin, $0.005 \%$ penicillin) for $12 \mathrm{~h}$. Finally, the COCs were treated with hyaluronidase and pronase, and oocytes were collected into fresh standard medium and used for transient transfection.

After $12 \mathrm{~h}$ of cultured, promoter luciferase reporter constructs were transfected into oocytes by Lipofectamine $^{\mathrm{TM}} 3000$ (Invitrogen, Carlsbad, CA, USA). A GFP reporter vector with CMV promoter were used to verify that the efficiency of transfection was greater than $85 \%$. For dual luciferase assay, each well was transfected with a 3:1 ratio of Lipofectamine ${ }^{\mathrm{TM}} 3000$ transfection reagent to total plasmids which included a 20:1 ratio of luciferase plasmids to PRL-TK vector (Renilla luciferase, Promega, Madison, WI, USA). pGL3/SV40-promoter vector (Promega, Madison, WI, USA) and pGL3-Basic 
vector served as the positive and negative controls, respectively. Each transfection experiment was carried out in triplicate.

After transfection with plasmids for $24 \mathrm{~h}$, the Firefly and Renilla luciferase activities of cells were measured using a Dual-Luciferase Reporter Assay System Kit (Promega, Madison, WI, USA) and VICTOR X2 Multilabel Plate Reader (PerkinElmer, Inc. Waltham, MA, USA). In each well, Firefly luciferase activity was normalized to Renilla luciferase activity. The activity of negative control pGL3-basicwas set to 1 .

\subsection{Statistical Analysis}

Real-time PCR results were analyzed by the $2^{-\Delta \Delta C t}$ method [31]. Statistical evaluation of the data was conducted in SPSS version 15.0 software (SPSS Inc, Chicago, IL, USA). One-way ANOVA test and bivariate correlations were used for statistical analysis. The data are presented as means \pm standard deviation (SD) of independent determinations.

\section{Results}

\subsection{The Tissue Expression of Ovine GDF9}

GDF9 mRNA levels were quantified using real-time PCR in ten tissues of STH sheep. After real-time PCR, the melting curve had only one peak and the amplification efficiency reached 2.013. The GDF9 mRNA level in the heart was arbitrarily set to 1. GDF9 mRNA levels in the ovary were significantly higher $(p<0.01)$ than in other tissues, with lower levels being found in the pituitary, liver, hypothalamus, spleen, cerebellum, uterus, lung, oviduct, and heart (Figure 1).

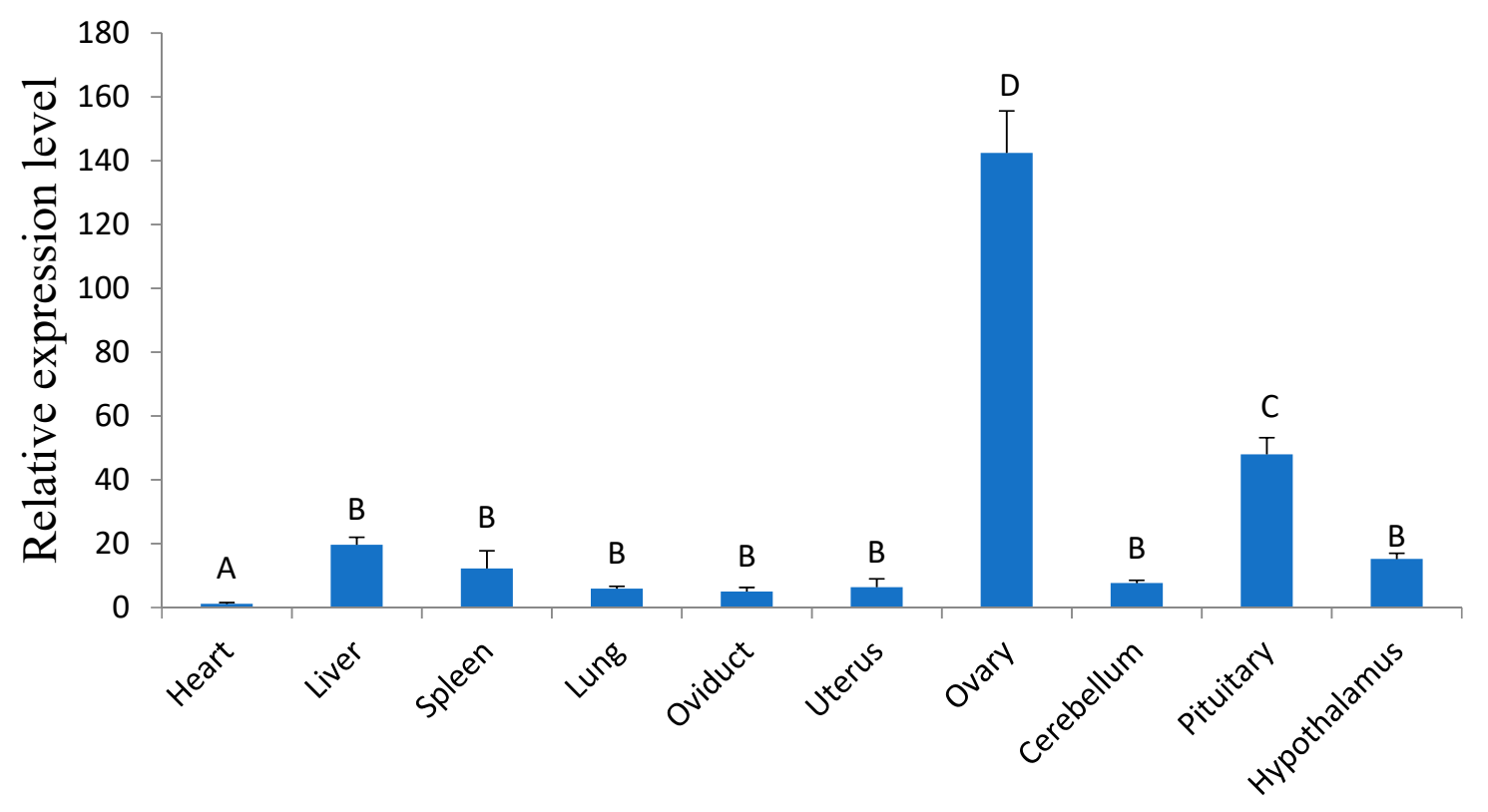

Figure 1. The tissue expression pattern of ovine GDF9. The real-time PCR results, the results were expressed as the means $\pm S D$, the different letters above the bars represent significant differences (Relative to the heart group of $\mathrm{A}, \mathrm{B}$, and $\mathrm{C}$ represent $p<0.01$, D represents $p<0.001$. Among $\mathrm{B}, \mathrm{C}$, and $\mathrm{D}$ differences represent $p<0.01$ ).

\subsection{Analysis of the GDF9 Promoter Region}

Analysis of the promoter revealed two CpG islands. A BSP primer was designed for the CpG island at position -1423 to -1854 , as it was closer to the transcription start site (TSS) (Figure 2A). This fragment included $29 \mathrm{CpG}$ sites and three transcription factor binding sites (Sp4, UCE.2, AP-2) (Figure 2B) (Table 2). 
A

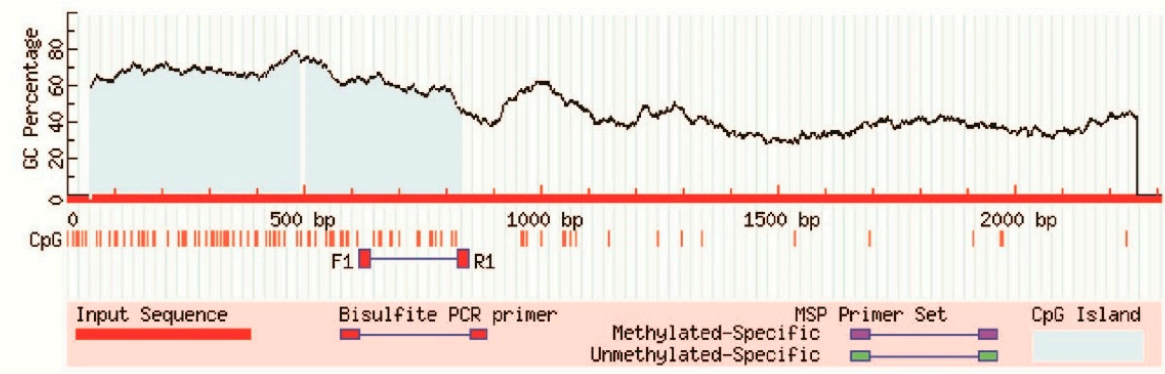

$\mathrm{B}$

1

2

AAGTGGGCGGTGCCTGCTCTGGGGTGGGGCCAAGCGCCTCTGGGCGGGCTCTGGGGT

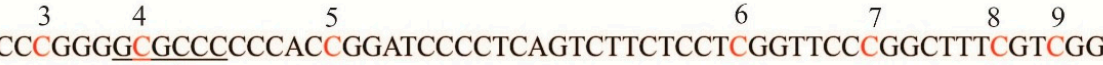
Sp4 $\begin{array}{ccccc} & 10 & 11 & 12 & 13\end{array}$ UCE. 2

TCAACCTCCAGAGCTGCCCTAGGGTCGGGTGTCCTGGCGCGGTGGAAAGGGTCTTTGA

TCAACCTCCAGAGCTGCCCTAGGGTCGGGTGTCCTGGCGCGGTGGAAAGGGTCTTTGA $18 \quad 19$ 2021 GGCCGCCGCCTGGCAGTCAACGCGAGATTTTGTACTGTCATGTCCAGTAAGCTGGAAC $22^{\text {AP-2 }} 23 \quad 24 \quad 25 \quad 26 \quad 27$ $28 \underset{29}{29}$ TCTGAGACTTCTCTTGTCGGCACCGGATAGAATCCACTGGCAGGGTGTAGCTG ovary

$\begin{array}{lllllllllllllllllllllllllllllll}\mathrm{C} & 1 & 2 & 3 & 4 & 5 & 6 & 7 & 8 & 9 & 10 & 11 & 12 & 13 & 14 & 15 & 16 & 17 & 18 & 19 & 20 & 21 & 22 & 23 & 24 & 25 & 26 & 27 & 28 & 29 & \text { Percentage of }\end{array}$

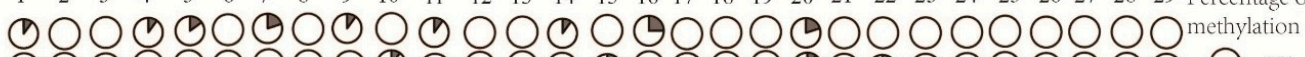
000000000000000000000000000000

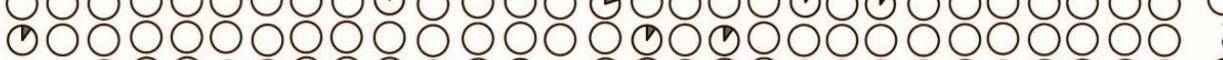
(2) heart

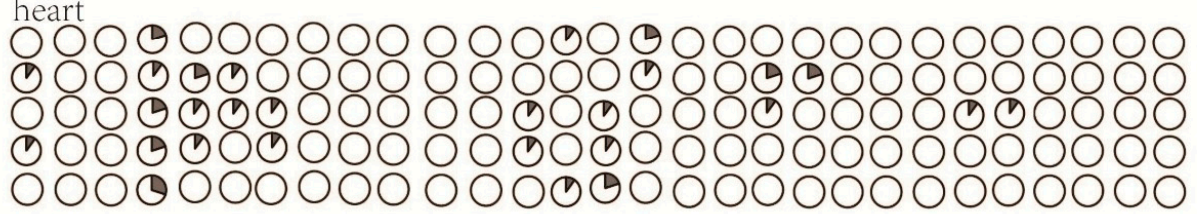

$\mathrm{D}$

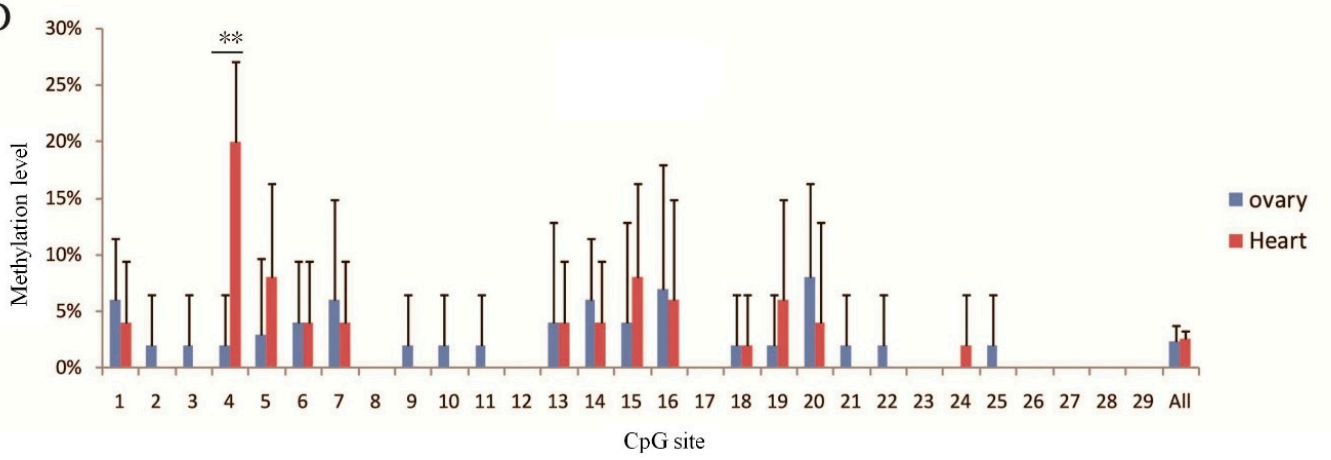

Figure 2. Methylation level of one CPG island ( -1453 to -1854) of ovine GDF9 in ovary and heart tissues. (A) The CpG island (sequences from F1 to R1) selected for methylation analysis. (B) The CpG site and transcription factor binding sites in this CPG island. A total of $29 \mathrm{CpG}$ sites (each site is numbered above) and three transcription factor binding sites (Sp4, UCE.2, AP-2, each sequence is underlined) are included. (C) Methylation levels of CpG sites in ovary and heart. Rows represent tissue from the five STH sheep; columns indicate $\mathrm{CpG}$ site. The overall methylation level was relatively low, and the level of mC-4 in heart was relatively high (20\%). (D) Histogram of methylation level of CpG sites. The mC-4 methylation level was significantly different $\left.{ }^{* *} p<0.01\right)$ between heart and ovary, and $\mathrm{mC}-4$ was coincidentally present on $\mathrm{Sp} 4$ transcription factor binding sites. 


\subsection{Methylation Level}

All CpG sites had low methylation levels (0-30\%), and the average level was only $2.52 \%$ (Figure 2C). However, the mC-4 level in heart (20\%) was significantly higher than that of other sites in either tissue type (Figure 2D) $(p<0.01)$. Interestingly, $\mathrm{mC}-4$ corresponded to a Sp4 transcription factor binding site (Figure 2B). The overall methylation level between heart and ovary was not significantly different $(p>0.05)$ (Figure 3A), but the mC-4 level in the ovary was significantly lower $(p<0.01)$ than that in heart (Figure 3B).

A

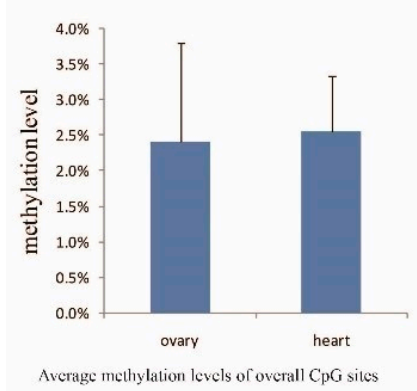

Average methylation levels of overall $\mathrm{CpG}$ sites

$\mathrm{D}$
B

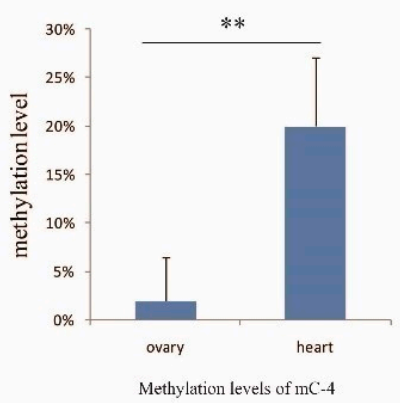

$\mathrm{C}$

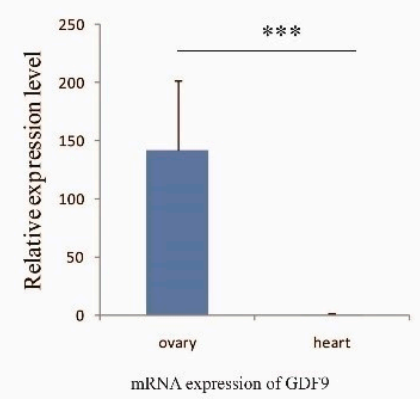

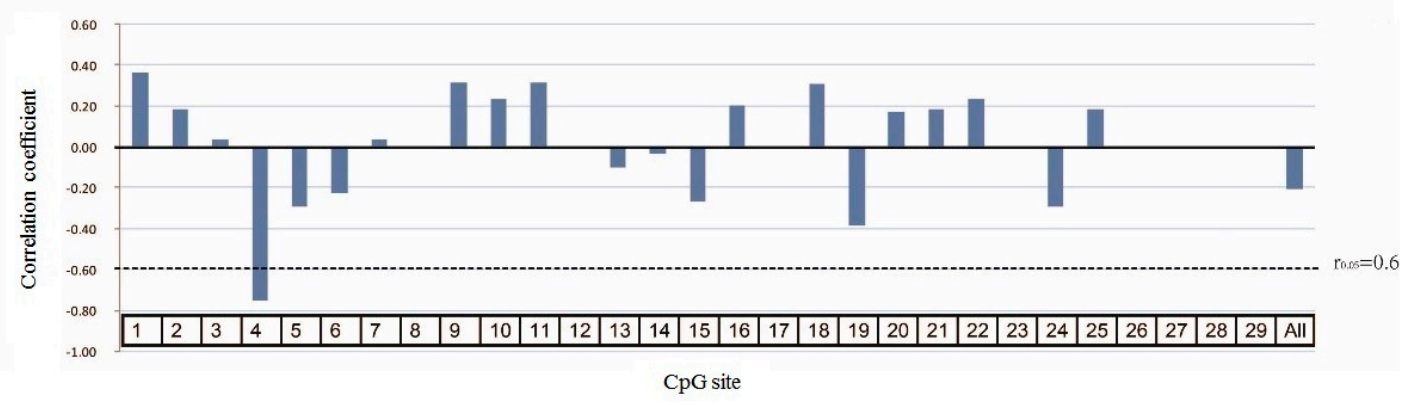

Figure 3. GDF9 mRNA expression and the correlation with methylation level. (A) The average methylation level of overall CPG sites, with no significant difference between heart and ovary. (B) The methylation level of mC-4 in ovary and heart, significantly lower in ovary than that in heart $(* * p<0.01)$. (C) The mRNA expression of GDF9 in ovary and heart, with significantly higher expression in ovary than that in heart $\left.{ }^{* * *} p<0.001\right)$. (D) Pearson's correlation coefficient for correlations between mRNA expression and methylation level. mRNA level was significantly correlated with methylation at the $\mathrm{mC}-4$ site. Dashed line $\left(\mathrm{r}_{0.05}\right)$ represents the correlation coefficient threshold.

\subsection{Correlation between the Methylation Level and mRNA Expression}

The expression of GDF9 was significantly higher in ovary than that in heart (Figure 3C) $(p<0.001)$. As Figure 3D showed, although the methylation level of $\mathrm{CpG}$ island was negatively correlated with GDF9 mRNA level $\left(\mathrm{R}=-0.21, \mathrm{r}_{0.05}=0.60\right)$, only the $\mathrm{mC}-4$ site showed a significant correlation coefficient $(\mathrm{R}=-0.75, p=0.012)$ (Figure $3 \mathrm{D})$.

\subsection{Identification of the Core Region of the Ovine GDF9}

All deletion constructs showed an increase in luciferase activity when compared with that of the pGL3-basic negative control. A significant increase $(p<0.05)$ of luciferase activity was observed in pGL3-basic-P6 (-1/-1987), when compared to pGL3-basic-P5 $(-1 /-1750)$, revealed that the core region of the GDF9 promoter was located between -1987 and -1750 (Figure 4). Interestingly, the mC-4 site $(-1790)$ occurred in this region. In addition, pGL3-basic-P7 showed significantly higher luciferase activity than that of pGL3-basic-P6 $(p<0.05)$, suggesting the region of -1987 to -2277 promoted relative luciferase activity. 


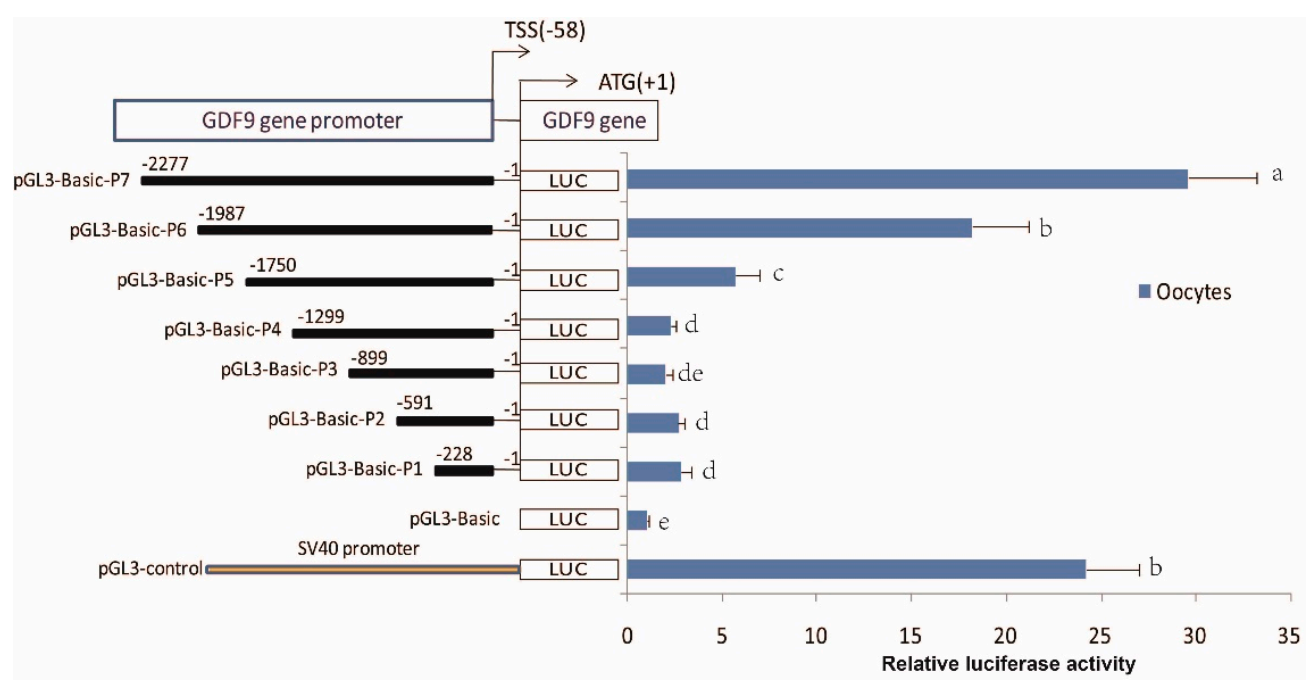

Figure 4. Identification of the core region of the ovine GDF9 promoter. Truncated $5^{\prime}$-flanking sequences of the GDF9 are labeled on the left panel and include pGL3-basic-P1 (-1/-228), pGL3-basic-P2 (-1/-591), pGL3-basic-P3 (-1/-899), pGL3-basic-P4 (-1/-1299), pGL3-basic-P5 (-1/-1750), pGL3-basic-P6 (-1/-1987), and pGL3-basic-P7 (-1/-2277). The luciferase activities of the promoter fragments in oocytes are shown on the right panel. Data of three independent replicates are presented as means \pm SD. Each of the adjacent lowercase letters represent significant differences $(p<0.05)$.

\subsection{Verification of the Effect of the $m C-4$ Site}

Constructs mutated at the $\mathrm{mC}-4$ site (pGL3-Basic-P6-mut1) and in vitro-methylation (pGL3-Basic-P6-mthylation) both showed similar luciferase activity and resulted in a 50\% reduction $(p<0.05)$ in promoter activity in comparison to that of wild type sequence (pGL3-Basic-P6), indicating that the $\mathrm{mC}-4$ site affected the activity of GDF9 promoter (Figure 5). To control for the effects of methylation in other regions, a luciferase assay was performed in pGL3-Basic-P5 and pGL3-Basic-P5-methylationtransfected cells, and found that those constructs had similar luciferase activity, implying that methylation has no effect on the region of -1 to -1750 (Figure 5).

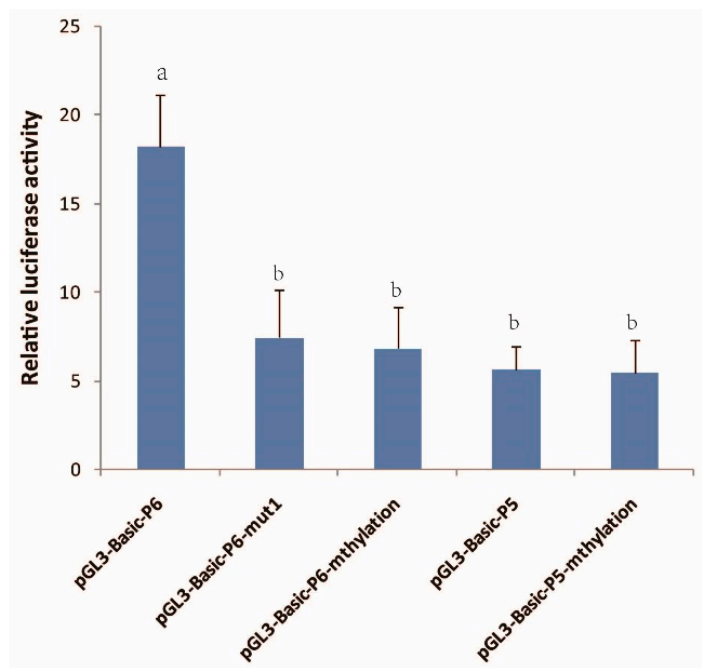

Figure 5. Verification of the effect of the mC-4 site by dual-luciferase. pGL3-Basic-P6-mut1 is site-directed mutation of mC-4; pGL3-Basic-P6-mthylation and pGL3-Basic-P5-methylation are under vitro-methylation; pGL3-basic-P5 and pGL3-basic-P6 are controls. Bars indicate means $\pm \mathrm{SD}$. Different superscripts indicate significant difference $(p<0.05)$. 


\section{Discussion}

The tissue expression pattern of GDF9 has been examined in many animals, with high expression levels in ovary $[14,32,33]$. In this study, ovine GDF9 expression was explored by real-time PCR, and GDF9 expression was significantly higher in ovary than in other tissues. This finding was similar to results from former studies using RT-PCR, RNA-sequencing, and FISH [15-17,22] and reinforces that GDF9 expressionis tissue-specific in sheep.

The underlying functional mechanisms contributing to the tissue-specific expression pattern of GDF9 remain unclear. A study found that a distal promoter NOBOX binding element $(-1881)$ can enhance expression of GDF9 in buffalo oocytes, therefore resulting in cell-specific expression [30]. However, ovine GDF9 lacks a NOBOX binding element, which implies that sheep may have a different regulation mechanism when compared to cattle.

Methylation is one of the most common mechanisms by which tissue-specific expression is regulated. Many genes exhibit tissue-specific expression due to the methylation of the $5^{\prime}$-flanking sequence, especially the $\mathrm{CPG}$ island $[27,34,35]$. In this study, methylation levels of CpG island $(-1453$ to -1854$)$ were relatively low with no difference between heart and ovary, but mC-4 exhibited significantly higher methylation levels in heart than in ovary. Whole genome bisulfite sequencing revealed that most of the genes, with the exception of silent genes, had low methylation levels in the $5^{\prime}$-flanking sequence [36]. Accordingly, GDF9 still had low expression levels in the heart, indicating that it is not a silent gene. Furthermore, DNA methylation of some important transcription factor binding sites, even given low methylation levels, can influence the expression of gene [27].

Interestingly, mC-4 presented on Sp4 transcription factor binding sites and the methylation level of this site were negatively correlated with the mRNA expression. Additionally, mutation or methylation of $\mathrm{mC}-4$ can significantly reduce basal transcriptional activity of the GDF9 promoter in oocytes $(p<0.05)$. Sp4, a member of the Sp1-family of zinc finger transcription factors, is required for normal murine male fertility [37]. Male Sp $4^{\text {null }}$ mice do not breed, and female Sp4 $4^{\text {null }}$ mice have a smaller uterus and they exhibit a pronounced delay in sexual maturation [38], which implies that Sp4 plays an important role in reproduction. Therefore, it is possible that Sp4 regulates GDF9 expression, thereby influencing reproduction. In this study, the ovary was characterized by high GDF9 expression with low methylation levels of $\mathrm{mC}-4$, while the opposite was observed in the heart. The methylation at the mC-4 site may inhibit the DNA-binding capacity of Sp4 and reduce GDF9 expression.

Finally, it is possible that additional sites may also influence gene expression because only one fragment of CpG island was analyzed, and other fragments (Figure 2A) still require further investigation. Furthermore, the region of $-1987 /-2277$ promoted the relative luciferase activity. Notably, three estrogen response elements (ERRG, ER2, ERRB) (Table 2) were detected in this region, and this binding site could be important for folliculogenesis.

\section{Conclusions}

In summary, the methylation status of the ovine GDF9 promoter CpG island mC-4 site might affect the binding of the Sp4 transcription factor, thereby regulating GDF9 expression and resulting in tissue-specific expression. This study provides useful information for understanding the role of GDF9 gene in the reproduction of sheep.

Author Contributions: Conceptualization, M.C. and Z.P.; Methodology, Z.P. and X.W.; Formal Analysis Q.L. R.D. Investigation Z.P. and X.G.; Resources, W.H. and X.X.; Data Curation, Z.P., X.C., X.H.; Manuscript draft, Z.P. and X.W.; Manuscript edition, S.L., F.L., H.W. and M.C. All authors reviewed the final version of manuscript.

Funding: This work was supported by National Natural Science Foundation of China (No. 31802031, No. 31772580), by Natural Science Foundation of Shandong Province (ZR2018BC045), by The Doctor Fund of Linyi University (No. LYDX2016BS068), by The Agricultural Science and Technology Innovation Program of China (No. ASTIP-IAS13), by The Earmarked Fund for China Agriculture Research System (No. CARS-38 and No. CAAS-XTCX2016011-02-02) and by Central Public-interest Scientific Institution Basal Research Fund (No. Y2017JC24). 
Acknowledgments: We thank farmers in Ningxia Hui Autonomous Region for sheep raising and sample collection. We thank Emily Aston for editing the English in the manuscript.

Conflicts of Interest: The authors declare no conflict of interest.

\section{References}

1. McPherron, A.C.; Lee, S.J. GDF-3 and GDF-9: Two new members of the transforming growth factor-beta superfamily containing a novel pattern of cysteines. J. Biol. Chem. 1993, 268, 3444-3449. [PubMed]

2. Dong, J.W.; Albertini, D.F.; Nishimori, K.; Kumar, T.R.; Lu, N.F.; Matzuk, M.M. Growth differentiation factor-9 is required during early ovarian folliculogenesis. Nature 1996, 383, 531-535. [CrossRef] [PubMed]

3. Melo, E.; Silva, B.; Castro, E.; Silva, T.; Paiva, S.; Sartori, R.; Franco, M.; Souza, C.J.; Neves, J. A novel mutation in the growth and differentiation factor 9 (GDF9) gene is associated, in homozygosis, with increased ovulation rate in Santa Ines sheep. Biol. Reprod. 2008, 78, 141. [CrossRef]

4. Nicol, L.; Bishop, S.C.; Pong-Wong, R.; Bendixen, C.; Holm, L.E.; Rhind, S.M.; McNeilly, A.S. Homozygosity for a single base-pair mutation in the oocyte-specific GDF9 gene results in sterility in Thoka sheep. Reproduction 2009, 138, 921-933. [CrossRef] [PubMed]

5. Silva, B.D.M.; Castro, E.A.; Souza, C.J.H.; Paiva, S.R.; Sartori, R.; Franco, M.M.; Azevedo, H.C.; Silva, T.A.S.N.; Vieira, A.M.C.; Neves, J.P.; et al. A new polymorphism in the Growth and Differentiation Factor 9 (GDF9) gene is associated with increased ovulation rate and prolificacy in homozygous sheep. Anim. Genet. 2011, 42, 89-92. [CrossRef] [PubMed]

6. Vage, D.I.; Husdal, M.; Kent, M.P.; Klemetsdal, G.; Boman, I.A. A missense mutation in growth differentiation factor 9 (GDF9) is strongly associated with litter size in sheep. BMC Genet. 2013, 14, 1. [CrossRef] [PubMed]

7. Souza, C.J.H.; McNeilly, A.S.; Benavides, M.V.; Melo, E.O.; Moraes, J.C.F. Mutation in the protease cleavage site of GDF9 increases ovulation rate and litter size in heterozygous ewes and causes infertility in homozygous ewes. Anim. Genet. 2014, 45, 732-739. [CrossRef] [PubMed]

8. Hanrahan, J.P.; Gregan, S.M.; Mulsant, P.; Mullen, M.; Davis, G.H.; Powell, R.; Galloway, S.M. Mutations in the genes for oocyte-derived growth factors GDF9 and BMP15 are associated with both increased ovulation rate and sterility in Cambridge and Belclare sheep (Ovis aries). Biol. Reprod. 2004, 70, 900-909. [CrossRef] [PubMed]

9. Pokharel, K.; Peippo, J.; Honkatukia, M.; Seppälä, A.; Rautiainen, J.; Ghanem, N.; Hamama, T.M.; Crowe, M.A.; Andersson, M.; Li, M.H. Integrated ovarian mRNA and miRNA transcriptome profiling characterizes the genetic basis of prolificacy traits in sheep (Ovis aries). BMC Genom. 2018, 19, 104. [CrossRef] [PubMed]

10. Jackowska, M.; Kempisty, B.; Wozna, M.; Piotrowska, H.; Antosik, P.; Zawierucha, P.; Bukowska, D.; Nowicki, M.; Jaskowski, J.M.; Brussow, K.P. Differential expression of GDF9, TGFB1, TGFB2 and TGFB3 in porcine oocytes isolated from follicles of different size before and after culture in vitro. Acta Vet. Hung. 2013, 61, 99-115. [CrossRef] [PubMed]

11. Nath, A.; Sharma, V.; Dubey, P.K.; Pratheesh, M.D.; Gade, N.E.; Saikumar, G.; Sharma, G.T. Impact of gonadotropin supplementation on the expression of germ cell marker genes (MATER, ZAR1, GDF9, and BMP15) during in vitro maturation of buffalo (Bubalus bubalis) oocyte. In Vitro Cell. Dev. Biol. Anim. 2013, 49, 34-41. [CrossRef] [PubMed]

12. Aaltonen, J.; Laitinen, M.P.; Vuojolainen, K.; Jaatinen, R.; Horelli-Kuitunen, N.; Seppa, L.; Louhio, H.; Tuuri, T.; Sjoberg, J.; Butzow, R.; et al. Human growth differentiation factor 9 (GDF-9) and its novel homolog GDF-9B are expressed in oocytes during early folliculogenesis. J. Clin. Endocrinol. Metab. 1999, 84, $2744-2750$. [CrossRef] [PubMed]

13. Zhang, Y.; Yuan, C.; Qin, F.; Hu, G.; Wang, Z. Molecular characterization of gdf9 and bmp15 genes in rare minnow Gobiocypris rarus and their expression upon bisphenol A exposure in adult females. Gene 2014, 546, 214-221. [CrossRef] [PubMed]

14. Pan, Z.Y.; Di, R.; Tang, Q.Q.; Jin, H.H.; Chu, M.X.; Huang, D.W.; He, J.N.; Liu, Q.Y.; Hu, W.P.; Wang, X.Y.; et al. Tissue-specific mRNA expression profiles of GDF9, BMP15, and BMPR1B genes in prolific and non-prolific goat breeds. Czech J. Anim. Sci. 2015, 60, 452-458. [CrossRef]

15. Hu, D.L.; Li, Q.F.; Xu, Y.F.; Li, E.L.; Han, Y.D.; Tu, F.; Xie, Z. The tissue expression profile, mRNA expression level and SNPs analysis on GDF9 gene in Hu sheep. J. Agric. Biotechnol. 2010, 18, 533-538. 
16. Clark, E.L.; Bush, S.J.; Mcculloch, M.; Farquhar, I.L.; Young, R.; Lefevre, L.; Pridans, C.; Tsang, H.G.; Wu, C.; Afrasiabi, C. A high resolution atlas of gene expression in the domestic sheep (Ovis aries). PLoS Genet. 2017, 13, e1006997. [CrossRef] [PubMed]

17. Jiang, Y.; Xie, M.; Chen, W.; Talbot, R.; Maddox, J.F.; Faraut, T.; Wu, C.; Muzny, D.M.; Li, Y.; Zhang, W. The sheep genome illuminates biology of the rumen and lipid metabolism. Science 2014, 344, 1168-1173. [CrossRef] [PubMed]

18. Kona, S.S.; Praveen Chakravarthi, V.; Siva Kumar, A.V.; Srividya, D.; Padmaja, K.; Rao, V.H. Quantitative expression patterns of GDF9 and BMP15 genes in sheep ovarian follicles grown in vivo or cultured in vitro. Theriogenology 2016, 85, 315-322. [CrossRef] [PubMed]

19. Feary, E.S.; Juengel, J.L.; Smith, P.; French, M.C.; O'Connell, A.R.; Lawrence, S.B.; Galloway, S.M.; Davis, G.H.; McNatty, K.P. Patterns of expression of messenger RNAs encoding GDF9, BMP15, TGFBR1, BMPR1B, and BMPR2 during follicular development and characterization of ovarian follicular populations in ewes carrying the Woodlands FecX2 ${ }^{\mathrm{W}}$ mutation. Biol. Reprod. 2007, 77, 990-998. [CrossRef] [PubMed]

20. Abdoli, R.; Zamani, P.; Deljou, A.; Rezvan, H. Association of BMPR-1B and GDF9 genes polymorphisms and secondary protein structure changes with reproduction traits in Mehraban ewes. Gene 2013, 524, $296-303$. [CrossRef] [PubMed]

21. Varnosfaderani, S.R.; Ostadhosseini, S.; Hajian, M.; Hosseini, S.M.; Khashouei, E.A.; Abbasi, H.; Hosseinnia, P.; Nasr-Esfahani, M.H. Importance of the GDF9 signaling pathway on cumulus cell expansion and oocyte competency in sheep. Theriogenology 2013, 80, 470-478. [CrossRef] [PubMed]

22. Bodensteiner, K.J.; McNatty, K.P.; Clay, C.M.; Moeller, C.L.; Sawyer, H.R. Expression of growth and differentiation factor-9 in the ovaries of fetal sheep homozygous or heterozygous for the inverdale prolificacy gene (FecX(I)). Biol. Reprod. 2000, 62, 1479-1485. [CrossRef] [PubMed]

23. Verma, A.D.; Parnaik, V.K. Identification of tissue-specific regulatory region in the zebrafish lamin A promoter. Gene 2015, 567, 73-80. [CrossRef] [PubMed]

24. Guske, K.; Schmitz, B.; Schelleckes, M.; Duning, K.; Kremerskothen, J.; Pavenstadt, H.J.; Brand, S.M.; Brand, E. Tissue-specific differences in the regulation of KIBRA gene expression involve transcription factor TCF7L2 and a complex alternative promoter system. J. Mol. Med. 2014, 92, 185-196. [CrossRef] [PubMed]

25. Bai, J.; Gong, W.; Wang, C.; Gao, Y.; Hong, W.; Chen, S.X. Dynamic methylation pattern of cyp19a1a core promoter during zebrafish ovarian folliculogenesis. Fish Physiol. Biochem. 2016, 42, 947-954. [CrossRef] [PubMed]

26. Li, S.; Jing, W.; Yin, X.; Sun, S.; Chen, Z.; Zhu, G.; Wu, S.; Bao, W. Identification of a 5-Methylcytosine Site that may Regulate $C / E B P \beta$ Binding and Determine Tissue-Specific Expression of theBPIGene in Piglets. Sci. Rep. 2016, 6, 28506.

27. Wu, W.; Ren, Z.; Liu, H.; Wang, L.; Huang, R.; Chen, J.; Zhang, L.; Li, P.; Xiong, Y. Core promoter analysis of porcine Six1 gene and its regulation of the promoter activity by CpG methylation. Gene 2013, 529, 238-244. [CrossRef] [PubMed]

28. Pan, Z.Y.; He, X.Y.; Liu, Q.Y.; Hu, W.P.; Wang, X.Y.; Guo, X.F.; Cao, X.H.; Di, R.; Chu, M.X. Cloning and genetic polymorphism analysis of mRNA, DNA and regulatory region of ovine GDF9 gene in 11 breeds. Acta Vet. Zootech. Sin. 2016, 47, 1555-1564.

29. Tu, Y.R. The Sheep and Goat Breeds in China; Shanghai Science and Technology Press: Shanghai, China, 1989.

30. Roy, B.; Rajput, S.; Raghav, S.; Kumar, P.; Verma, A.; Kumar, S.; De, S.; Goswami, S.L.; Datta, T.K. A reporter promoter assay confirmed the role of a distal promoter NOBOX binding element in enhancing expression of GDF9 gene in buffalo oocytes. Anim. Reprod. Sci. 2012, 135, 18-24. [CrossRef] [PubMed]

31. Livak, K.J.; Schmittgen, T.D. Analysis of relative gene expression data using real-time quantitative PCR and the 2(-Delta Delta C(T)) Method. Methods 2001, 25, 402-408. [CrossRef] [PubMed]

32. Fitzpatrick, S.L.; Sindoni, D.M.; Shughrue, P.J.; Lane, M.V.; Merchenthaler, I.J.; Frail, D.E. Expression of growth differentiation factor-9 messenger ribonucleic acid in ovarian and nonovarian rodent and human tissues. Endocrinology 1998, 139, 2571-2578. [CrossRef] [PubMed]

33. Hosoe, M.; Kaneyama, K.; Ushizawa, K.; Hayashi, K.G.; Takahashi, T. Quantitative analysis of bone morphogenetic protein 15 (BMP15) and growth differentiation factor 9 (GDF9) gene expression in calf and adult bovine ovaries. Reprod. Biol. Endocrinol. 2011, 9, 1-8. [CrossRef] [PubMed] 
34. Shang, X.; Su, J.; Wan, Q.; Feng, X. CpG methylation in the $5^{\prime}$-flanking region of LGP2 gene lacks association with resistance/susceptibility to GCRV but contributes to the differential expression between muscle and spleen tissues in grass carp, Ctenopharyngodon idella. Fish Shellfish Immunol. 2014, 40, 154-163. [CrossRef] [PubMed]

35. Huse, S.M.; Gruppuso, P.A.; Boekelheide, K.; Sanders, J.A. Patterns of gene expression and DNA methylation in human fetal and adult liver. BMC Genom. 2015, 16, 981. [CrossRef] [PubMed]

36. Lister, R.; Pelizzola, M.; Dowen, R.H.; Hawkins, R.D.; Hon, G.; Tontifilippini, J.; Nery, J.R.; Lee, L.K.; Ye, Z.; Ngo, Q. Human DNA methylomes at base resolution show widespread epigenomic differences. Nature 2009, 462, 315-322. [CrossRef] [PubMed]

37. Supp, D.M.; Witte, D.P.; Branford, W.W.; Smith, E.P.; Potter, S.S. Sp4, a member of the Sp1-family of zinc finger transcription factors, is required for normal murine growth, viability, and male fertility. Dev. Biol. 1996, 176, 284-299. [CrossRef] [PubMed]

38. Gollner, H.; Bouwman, P.; Mangold, M.; Karis, A.; Braun, H.; Rohner, I.; Del Rey, A.; Besedovsky, H.O.; Meinhardt, A.; van den Broek, M.; et al. Complex phenotype of mice homozygous for a null mutation in the Sp4 transcription factor gene. Genes Cells 2001, 6, 689-697. [CrossRef] [PubMed]

(C) 2018 by the authors. Licensee MDPI, Basel, Switzerland. This article is an open access article distributed under the terms and conditions of the Creative Commons Attribution (CC BY) license (http://creativecommons.org/licenses/by/4.0/). 